Vincenzo Guidetti

Federica Galli

Rita Cerutti

Paola Fabrizi

\section{Chronic daily headache in developmental ages: diagnostic issues}

typical that migraine changes over time, taking tension features with almost daily crises. Headache with onset in children or adolescents presents age-related characteristics and the classification system should be better tailored to the peculiarities of this clinical phenomenology. Having a strong diagnostic system is the sine qua non of further investigations in epidemiology, etiopathogenesis, and therapy of $\mathrm{CDH}$.

Key words Children • Classification • Chronic daily headache

\author{
V. Guidetti $(\varangle) \cdot$ F. Galli • R. Cerutti \\ of Headaches, \\ Childhood Headache Center, \\ Via dei Sabelli 108, I-00185, Rome, Italy \\ e-mail: v.guidetti@chiadache.org \\ Tel.: +39-06-44712255 \\ Fax: +39-06-4957857
}

\begin{abstract}
Chronic daily headache CDH) in children and adolescents presents features not sufficiently recsystem. The aim of our study was to analyze the applicability of adult $\mathrm{CDH}$ classification in child and adolescent clinical populations, outlining similarities and differences. In the developmental age, frequent and severe migraine attacks may overlap daily crises of tension-type headache. The clinical onset features are similar to the subsequent (chronic) trend, while in adults, it is more
\end{abstract}

In adult migraineurs, the use of over-the-counter medication ranges from $60 \%$ to $90 \%[9,10]$. Overuse may predispose to $\mathrm{CDH}$ with symptomatic drug dependence and refractoriness to prophylactic medication [11]. Adult patients with $\mathrm{CDH}$ frequently refer that the onset of headache was during their infancy or adolescence [4-7]. In spite of the clinical relevance and disabilities related to $\mathrm{CDH}$, the study of $\mathrm{CDH}$ in adults, children and adolescents is only at the initial stages. Studies of the etiopathogenesis, diagnosis, prognosis, and therapy of $\mathrm{CDH}$ are lacking.

The diagnosis of chronic daily headache is function of a quantitative parameter (an almost daily frequency of the crises). We do not have clear qualitative parameters (a certain symptomatological characterization of the crises).

International Headache Society (IHS) classification [12] does not provide criteria to classify $\mathrm{CDH}$, which is considered only as "previous term" to name the current chronic tension-type headache. tions compared to adult ages. However, even in pediatric ages the occurrence of "rebound headache" has been described [8]. 
Studies on clinical and prognostic features of CDH lack common diagnostic criteria, and in developmental ages the diagnosis is even more troublesome, since the clinical characterization shows unclear aspects.

The clinical phenomenology of headache in developmental ages presents age-related characteristics that make the applicability of the IHS criteria troublesome [12]. Modifications have been suggested over time [13-20]. The classification of $\mathrm{CDH}$ is even more complicated, inasmuch as international diagnostic criteria are unsatisfactory even for adult patients. Attempts to classify adult $\mathrm{CDH}$ patients according to IHS criteria (without ad hoc modifications) have not been feasible in over one-third of cases $[20,21]$.

Silberstein et al.'s classification [22] represents the first attempt at a better systematization of the argument, by the proposal of diagnostic categories to classify primary and secondary varieties of $\mathrm{CDH}$. The primary varieties (each with or without drug overuse) are:

- Transformed migraine, history of episodic migraine (with or without aura), in teens or twenties with episodic migraine and later development of $\mathrm{CDH}$. It is often difficult to distinguish among headache sub-types. These patients frequently have a family history of migraine, menstrual aggravation, identifiable trigger factors, and unilateral headache.

- Chronic tension-type headache, history of episodic tension-type headache or de novo headache. Patients meet IHS criteria for chronic tension-type headache. The headaches are more often diffuse and bilateral, frequently involving the posterior aspect of the head and neck, and may have some migrainous features. The major difference with transformed migraine is the absence of a clear history of episodic migraine.

- New daily persistent headache, patients may refer fairly rapid-onset headache, some remember the exact day or time when the headache started. Head pain is continuous, and there is no a clear history of episodic migraine or tension-type headache. The patients are generally younger than those with transformed migraine.

- Hemicrania continua, continuous but fluctuating, moderately severe, unilateral headache that can alternate sides, phono- and photophobia, nausea, and tearing. Headache is not triggered by neck movements, but tender spots can occur in the neck.

- Indomethacin-responsive headache disorder may be occasionally associated with autonomic disturbances, such as ptosis, mydriasis and sweating.

The latter are post-traumatic headaches, cervical spine disorders, headache associated with vascular disorders, headache associated with nonvascular disorders, and others.

The application of Silberstein et al.'s model [22] in the youngest age does not give us an exhaustive diagnostic framework, but it opens to the hypothesis of specific symp- tomatological expression of $\mathrm{CDH}$ in children and adolescents. By the application of Silberstein et al.'s criteria [22], Gladstein and Holden [23] found that $45 \%$ of children and adolescents did not fit into these categories. However, by adding a category called comorbid (migraine crises in comorbid association with tension-type headache), all but one of 37 patients could be classified according to Silberstien et al.'s 1994 criteria.

The aim of our study was to analyze the clinical features of $\mathrm{CDH}$ with childhood or adolescence onset on the basis of the current status of knowledge. The symptoms of $\mathrm{CDH}$ in children and adolescents present age-related features [24] and do not overlap with adult characteristics. Developmental factors, onset age, comorbidities and several other factors influence the clinical phenomenology, the time trend and the outcome of $\mathrm{CDH}$, even if little is known about them. Two points seem to differentiate the child or adolescent clinical expression of $\mathrm{CDH}$ compared to the adult form. On one hand, in the developmental age, frequent and severe migraine attacks overlap daily crises of tension-type headache. The onset clinical features are similar to the subsequent (chronic) trend. On the other hand, in adults, the tendency of migraine to change over time is more typical, taking tension features with almost daily crises. About $30 \%$ of adult $\mathrm{CDH}$ sufferers are "unclassifiable" according to IHS criteria [11, 25]. Either the symptomatological features of the crises are incompatible with IHS criteria for chronic tension-type headache, because specific migraine symptoms occur, or the length of the attacks exceeds 72 hours (over the border term accepted for migraine).

\section{Materials and methods}

Out of 571 subjects examined in our headache center in 1996, we selected $81 \mathrm{CDH}$ patients for further study.

On the basis of almost daily headache attacks, IHS criteria (chronic tension-type headache) were integrated with Silberstein et al.'s criteria [22]. In addition, we distinguished between the time trend of $\mathrm{CDH}$ (new onset or transformation of other types over time) and the clinical phenomenology: mixed headache (migraine and tension-type features in the same attack), or chronic tensiontype headache and comorbid headache (migraine episodes clearly distinguishable by near daily tension-type headache).

\section{Results}

We studied 81 patients with $\mathrm{CDH}$, including 54 girls and 27 boys. The patients' mean age was 12.3 years $(\mathrm{SD}=2.1$ years; range, $7-18$ years). The mean age at $\mathrm{CDH}$ presentation was 8.3 years $(\mathrm{SD}=2.8)$ in boys and 9.1 years $(\mathrm{SD}=2.7)$ in girls. 
Table 1 Diagnosis of $\mathrm{CDH}$ in 81 children, according to the temporal presentation

\begin{tabular}{|c|c|c|c|c|c|}
\hline & \multicolumn{5}{|c|}{ Patients, n (\%) } \\
\hline & Mixed & Chronic tension-type & Comorbid & & Total \\
\hline $\mathrm{CDH}$ at onset & $(70.6)$ & $(52.4)$ & 0 & 47 & $(58.2)$ \\
\hline Transformation from other types & $(29.4)$ & $(47.6)$ & (26.5) & 34 & $(41.8)$ \\
\hline Total & $51 \quad(62.9)$ & $21 \quad(25.9)$ & $(11.1)$ & 81 & $(100.0)$ \\
\hline
\end{tabular}

Table 2 Diagnosis of $\mathrm{CDH}$ per gender in the 81 children

\begin{tabular}{|c|c|c|c|c|c|c|c|c|c|c|}
\hline & \multicolumn{5}{|c|}{ New onset } & \multicolumn{4}{|c|}{ Transformed } & \multirow[t]{2}{*}{ Total } \\
\hline & & $\begin{array}{l}\text { lixed } \\
\text { adache }\end{array}$ & $\begin{array}{l}\text { Chronic } \\
\text { tension-type }\end{array}$ & $\begin{array}{l}\text { Comorbid } \\
\text { headache }\end{array}$ & Total & $\begin{array}{c}\text { Mixed } \\
\text { headache }\end{array}$ & $\begin{array}{l}\text { Chronic } \\
\text { tension-type }\end{array}$ & $\begin{array}{l}\text { Comorbid } \\
\text { headache }\end{array}$ & Total & \\
\hline Boys & 9 & $(25.0)$ & $2(18.2)$ & 0 & $11(23.4)$ & $6(40.0)$ & $4 \quad(40.0)$ & $6 \quad(66.7)$ & $16(47.1)$ & 27 (33.3) \\
\hline Girls & 27 & $(75.0)$ & 9 (81.9) & 0 & $36(76.6)$ & $9(60.0)$ & $6 \quad(60.0)$ & $3 \quad(33.3)$ & $18(52.9)$ & $54(66.7)$ \\
\hline Total & 36 & (44.4) & 11 (13.6) & 0 & $47(58.0)$ & $15(18.5)$ & $10(12.3)$ & $9 \quad(11.1)$ & $34(42.0)$ & 81 \\
\hline
\end{tabular}

Table 1 shows the prevalence and temporal presentation of $\mathrm{CDH}$. Mixed headache was the most prevalent (62.9\%): in $70.6 \%$ of the cases it occured at onset. Comorbid pattern (migraine and tension-type headache) was never displayed at onset, but developed exclusively from other types of headache. We found no difference between onset or transformed chronic tension-type. $\mathrm{CDH}$ at onset outnumbered the transformed types $(58.2 \%$ vs. $41.8 \%)$. Of the patients with transformed headache, $9(26.5 \%)$ presented a basis of tension-type headache (in $80 \%$ chronic tension-type) plus episodic migraine crises $(67 \%$ without aura and $33 \%$ with aura). Chronic tension-type headache was characterized by de novo onset of daily crises in half of the cases.

Table 2 shows the characteristics of $\mathrm{CDH}$ per gender. $\mathrm{CDH}$ prevailed in girls (66.7\%\% vs. $33.3 \%$ in boys) and in all single diagnostic categories, except transformed comorbid headache.

The prevalence among girls was stronger at onset (44.4\%) compared to transformed CDH (22.2\%). Boys showed onset $\mathrm{CDH}$ in $12.6 \%$ and transformed headache in $19.8 \%$ of the cases.

\section{Discussion}

The applicability of Silberstein et al.'s diagnostic categories [22] has shown shortcomings in developmental ages, needing addition and modifications. We worked on a double level: the clinical characteristics of headache and the temporal presentation. The diagnostic framework should necessarily distinguish between the time view (de novo onset or transformation of previous pattern) and the clinical view (the clinical phenomenology within the temporal pattern). Only this differentiation allowed the inclusion and diagnosis of all patients.

The presence of age-related symptomatological features needs closer examination, although the difficulty in obtaining a careful description of the symptoms by the child may represent an obstacle for a clear and unequivocal diagnosis. However, the existence of specific diagnostic categories and age-related characteristics of the symptoms needs further studies.

Gladstein and Holden [23] found the pattern classified as "comorbid headache" in $35 \%$ of the sample. We found it in about $11 \%$ of our sample, only among transformed headache patients. This finding supports the importance of a temporal differentiation in the classification of $\mathrm{CDH}$. The diagnostic category of mixed headache catches most of our patients and needs further examination in order to reach a better discrimination of the clinical characteristics, even according to de novo or transformed presentation of the crises.

However, several other points need to be clarified. The most relevant obstacle to the systematization of several issues related to $\mathrm{CDH}$ remains the lack of a sound diagnostic system of classification. Once we will have a common diagnostic system to classify $\mathrm{CDH}$ in children and adolescents, more easily we can analyze other important issues 
related to $\mathrm{CDH}$ with developmental age onset. However, the classification of child or adolescent $\mathrm{CDH}$ using the current adult (although provisional) diagnostic categories may cause additional difficulties. $\mathrm{CDH}$ with de novo onset prevails in the youngest patients, but the clinical and differential characteristics need to be clarified with respect to adults and to different stages of patient development. Our proposal of classification allowed the diagnosis of all patients, even though it requires further investigations to guarantee the full applicability.

Once we will have defined adequate diagnostic categories to pursue the standardization of the $\mathrm{CDH}$ classification, several other questions compel attention. The prevalence and incidence rates need to be clarified. Etiological determinants (do they differ in relation to the clinical phenomenology of the crises? which is the role of genetic or environmental factors?), therapeutical interventions (how to manage pharmacological treatment on the basis of our knowledge of the problems related to rebound headache? what about non-drug therapy for $\mathrm{CDH}$ ?), the process and the factors related to the chronicization of the crises (which is the difference compared to adult $\mathrm{CDH}$ ? which is the role of stress? which are the predisposing factors to the development of CDH?) are aspects to clarify. Finally, the issues of rebound headache and analgesic overuse need special attention especially in the youngest patients. The risk of rebound headache since pediatric age has been outlined [8].

The impact of $\mathrm{CDH}$ on a patient's daily life (and on the family) is severe, with consequences on school achievement, peer relationships, and other activities. In spite of the serious impact of $\mathrm{CDH}$ on the patient and family, we are still at the initial steps in systematization of the subject. Little is known about $\mathrm{CDH}$ from etiopathogenesis to diagnosis and therapy. The study of $\mathrm{CDH}$ should be pursued, taking into account the peculiarities of developmental age onset from diagnosis to therapy. During pediatric age, the culture of a correct drug intake assumes preventive significance. Starting in childhood, the prevention of drug overuse should be pursued as part of general management, and both parents and patients should be alerted to the risk of drug overuse.

\section{References}

1. Sillanpaa M, Piekkala P, Kero P (1991) Prevalence of headache at preschool age in unselected child population. Cephalalgia 11:239-242

2. Abu-Arefeh I, Russell G (1994) Prevalence of headache and migraine in schoolchildren. BMJ 309:765-769

3. Silberstein SD (1993) Tension-type and chronic daily headache. Neurology 43:1644-1649

4. Mathew NT, Stubits E, Nigam MR (1982) Transformation of episodic migraine into daily headache: analysis of factors. Headache 22:66-68

5. Mathew NT, Kurman R, Perez F (1990) Drug induced refractory headache-clinical features and management. Headache 30:634-638

6. Mathew NT (1991) Chronic daily headache: clinical features and natural history. In: Nappi G, Bono G, Sandrini G, Martignoni E, Miceli G (eds) Headache and depression. Raven, New York, pp 49-58

7. Silberstein SD (1991) Appropriate use of abortive medication in headache treatment. Pain Management 4:22-28

8. Vasconcellos E, Piña-Garza JE, Millan EJ, Warner JS (1998) Analgesic rebound headache in children and adolescence. J Child Neurol 13:443-447
9. Celentano DD, Stewart WF, Lipton RB, Reed ML (1992) Medication use and disability among migraineurs: a national probability sample survey. Headache 32:223-228

10. Edmeads J, Findlay H, Tugwell P, Pryse-Phillips W, Nelson RF, Murray TJ (1993) Impact of migraine and tension-type headache on life-style, consulting behaviour, and medication use: a Canadian population survey. Can J Neurol Sci 20:131-137

11. Solomon S, Lipton RB, Newman LC (1992) Clinical features of chronic daily headache. Headache 32:325-329

12. Headache Classification Committee of the International Headache Society (1988) Classification and diagnostic criteria of headache disorders, cranial neuralgias and facial pain. Cephalalgia 8[Suppl 7]:1-96

13. Guidetti V, Bruni O, Cerutti R et al (1991) How and why childhood headache and migraine differ from that of the adults. In: Gallai V, Guidetti V (eds) Juvenile headache. Excerpta Medica, Amsterdam, p 27

14. Metsähonkala L, Sillanpää M (1994) Migraine in children - an evaluation of the IHS criteria. Cephalalgia 14:285-290
15. Hamalainen ML, Hoppu K, Santavouri PR (1995) Effect of age on the fulfillment of the IHS criteria for migraine in children at a headache clinic. Cephalalgia 15:404-409

16. Winner P, Martinez W, Mate L, Bello L (1995) Classification of pediatric migraine: proposed revision to the IHS criteria. Headache 35:407-410

17. Seshia SS (1996) Specifity of IHS criteria in childhood headache. Headache 36:295-299

18. Wöber-Bingol C, Wöber C, Karwautz A et al (1996) IHS criteria for migraine and tension-type headache in children and adolescents. Headache 36:231-238

19. Raieli V, Raimondo D, Gangitano M, D'Amelio M, Cammalleri R, Camarda R (1996) The IHS Classification criteria for migraine headaches in adolescents need minor modifications. Headache 36:362-366

20. Solomon S, Lipton RB, Newman LC (1992) Evaluation of chronic daily headache-comparison to criteria for chronic tension-type headache. Cephalalgia 12:365-368

21. Messinger HB, Spierings ELH, Vincent AJP (1991) Overlap of migraine and tension-type headache in the International Headache Society classification. Cephalalgia 11:233-237 
22. Silberstein SD, Lipton RB, Solomon S, Mathew NT (1994) Classification of daily and near-daily headaches: proposed revisions to the HIS criteria. Headache 34:1-7
23. Gladstein J, Holden EW (1996)

Chronic daily headache in children and adolescents: a 2 year prospective study. Headache 36:349-351

24. Gladstein J, Holden EW, Winner P, Linder S et al (1997) Chronic daily headache in children and adolescents: current status and recommendations for the future. Headache 37:626-629
25. Manzoni GC, Granella F, Sandrini G, Cavallini A, Zanferrani C, Nappi G (1995) Classification of chronic daily headache by International Headache Society criteria: limits and new proposals. Cephalalgia 15:37-43 